\title{
AS VARIAÇÕES DA LÍNGUA PORTUGUESA NO ÂMBITO DO APLICATIVO WHATSAPP
}

Kleiton BORGES

Pós-graduação em Linguística - Universidade Federal do Pará

RESUMO: Este trabalho tem por objetivo mostrar uma pesquisa de campo sobre as variações linguísticas encontradas através do aplicativo WhatsApp, este, por sua vez, utilizado em plataformas específicas e aparelhos eletrônicos, como tablets e smartphones. Para isto, necessitou-se utilizar uma metodologia através de questionários e de entrevistas entre jovens e adultos, com o escopo de encontrar as variações que a língua portuguesa sofre no contexto entre seus usuários deste aplicativo nas conversas interacionais. A interação e a Internet ganharam espaço para pesquisas na área da Sociolinguística, pois permitiu o surgimento de uma nova linguagem e comunicação no meio virtual. Nesse sentido, utiliza-se o conceito de Internetês para diferenciar a conversação pessoal do texto escrito. Jovens e adultos passaram a se comunicar de uma forma despreocupada com a formalidade e apresentam uma nova variação linguística, deixando de lado as regras gramaticais normativas e trazendo uma reconfiguração no aspecto social digital, além das dinâmicas interacionais. Portanto, faz-se necessário buscar referenciais teóricos sobre a análise da conversação em Modesto (2011) e Marcuschi (2001), sobre língua, linguagem e variação linguística em Calvet (2002) e Maciel (2008) e sobre Internetês em Lahm, Pinho, Ribas e Ribas (2007). Como resultado, percebeuse que as maiores ocorrências foram as abreviações "pq" (porque) e do "vc" (você) com sete ocorrências, enquanto que "tb/tbm" (também) obtiveram seis ocorrências. Os termos "q" (que) e "n/num" (não) obtiveram quatro ocorrências, enquanto que outros termos foram poucas vezes utilizados. Concluiu-se que existem várias formas de expressões e palavras no âmbito do aplicativo, pois a linguagem utilizada no meio virtual está diretamente atrelada ao tempo e espaço da interação, sendo necessária a abreviação para uma interação virtual síncrona em que requer agilidade e rapidez de seus usuários.

PALAVRAS-CHAVE: Sociolinguística; Variação linguística; WhatsApp.

ABSTRACT: This paper has the aim to show a field research about the linguistic variations found through WhatsApp application, this, in turn, used in specific platforms and electronic devices, as tablets and smartphones. For this, it was necessary to use a methodology through questionnaires and interviews between Young people and adults, in order to find out the variations that the Portuguese language has in context between its users of this application in interaction conversations. The interaction and the Internet gained space for researches in Sociolinguistic's areas, because allowed the emergence of a new language and communication on virtual environment. In this sense, the concept of Internetês is used for differentiate personal conversation from written text. Young people and adults started to communicate in a carefree way with the formality and present a new linguistic variation, leaving aside the normative grammar rules and bringing a reconfiguration on digital social aspect, beyond interaction dynamics. Therefore, it is necessary to search theoretical references about conversation analysis in Modesto (2011) and Marcuschi (2001), about language, speech and linguistic variation in Calvet (2002) and Maciel (2008) and Internetês in Lahm, Pinho, Ribas and Ribas (2007). As result, it was noticed that the most occurrences were the abbreviations "pq" (why) and "vc" (you) with seven occurrences, while "tb/tbm" (also) obtained six occurrences. The terms " $q$ " (that) and "n/num" (no) obtained four occurrences, while other terms were used few times. It was concluded that there are various forms of expressions and words on application's scope, because the language used on virtual 
environment is directly linked to the time and space of the interaction, being necessary the abbreviation for a synchronous virtual interaction in which it requires agility and speed of its users.

KEYWORDS: Sociolinguistic; Linguistic variation; WhatsApp.

\section{Introdução}

A Sociolinguística é uma ciência que foca a língua e as perspectivas encontradas na sociedade em que se origina. As características encontradas nesta ciência podem ser elencadas como fatores geográficos, gênero, etnia, profissão, dentre outros. Cada grupo da sociedade pode apresentar um modo de falar próprio e diverge em relação a outros grupos, apresentando a variação linguística.

Nesta ciência, a interação e a Internet ganharam espaço como fatores importantes e consideráveis para pesquisas e estudos da área, pois permitiu o surgimento de uma nova linguagem desenvolvida através da comunicação e interação virtual, o que diferencia da conversação tradicional face a face e dos textos escritos.

Com as tecnologias atuais, jovens e adultos passaram a se comunicar frequentemente através de textos escritos, como os dispositivos móveis, se expressando de uma forma despreocupada com a formalidade e apresentando uma nova variação linguística em particular, deixando de lado as regras gramaticais normativas, trazendo uma reconfiguração nos aspectos técnicos e sociais digitais, além das dinâmicas interacionais na contemporaneidade.

Este trabalho se baseia sobre análise da conversação e seu uso no contexto virtual, pela qual Marcuschi (2001, p. 15) elabora uma breve definição sobre conversação, mencionando que é "uma interação verbal centrada, que se desenvolve durante o tempo em que dois ou mais interlocutores voltam sua atenção visual e cognitiva para uma tarefa comum". Também se comenta sobre variação linguística, em que ela representa formas variadas próprias em uma determinada região ou grupo de falantes. A interação entre eles é sua realidade e isso implica, no caso da língua portuguesa, formas diferentes de se falar, sendo que não existem as formas corretas e as formas erradas, mas sim, são apenas diferentes e se fazem entender dessa diferença (CALVET, 2002).

Aborda-se também o Internetês, um neologismo e uma adaptação linguística no contexto da comunicação ou diálogo virtual e tem por objetivo encurtar o tempo gasto em escrever certas palavras e sem perder o foco das informações que se passa no ambiente, sendo que este curto espaço de tempo requer também do usuário a apropriada abreviação gramatical na produção escrita, dispensando diretamente as formalidades (HORA, 2011).

O aplicativo (app) WhatsApp, sendo o objeto de estudo deste trabalho, é um mensageiro gratuito conhecido e popular em vários países. Ele tem a capacidade de criar conversas particulares com uma pessoa presente na lista de contatos do celular ou smartphone, de criar grupos de usuários (de trabalho, de família, de escola, de amigos e etc.) e 
compartilhar fotos, áudios e vídeos com esses usuários (FERREIRA, 2013, p. 5; POLLARD, 2015, p. 25).

Portanto, este trabalho aborda a análise da conversação, a variação linguística e o Internetês, tendo como objetivo uma pesquisa de campo com entrevistas para identificar quais são as variações linguísticas do português encontradas no âmbito do aplicativo WhatsApp.

\section{Análise da conversação e variação linguística}

Conforme o tempo e espaço tendem a avançar e se modificar, a língua e o desenvolvimento de novas formas de comunicação vão se transformando, se inovando e continuarão presentes ao homem e isso faz com que ela seja o diferencial dentre outros seres vivos. Segundo Modesto (2011, p. 19), "a conversação é uma prática social de que prescinde todas as outras práticas na vida social", pois o ser humano é dotado da habilidade da fala e de se comunicar e tem a oportunidade de se relacionar com seus semelhantes com propósitos e objetivos próprios, desenvolvendo trabalhos cooperativos e fazendo jus ao seu papel social. Portanto, a conversação, sendo um fenômeno social, tem por escopo "unir as pessoas em torno de um objetivo, que é comunicar".

Já para Marcuschi (2001, p. 15), a definição de conversação é "uma interação verbal centrada, que se desenvolve durante o tempo em que dois ou mais interlocutores voltam sua atenção visual e cognitiva para uma tarefa comum". Para Hilgert (apud MODESTO, 2011, p. 20), a conversação se baseia na comunicação prática e cotidiana, sendo que os interlocutores desenvolvem este processo de emissor e receptor e sempre há uma regra de comportamentos inerentes aos participantes da comunicação. Este processo da conversação compreende alguns fatores como normas sociais, conduta, norma gramatical e a sua correta utilização em determinado contexto situacional.

Sendo assim, os estudos da análise da conversação se voltam para a organização estrutural institucionalizada existente na interação social, analisando, também, processos cooperativos no ato real dos diálogos, e isso se explica o porquê dela dá importância aos fatores que a fazem ser interessante, como as trocas de turnos, o momento dos silêncios, a fala feita ao mesmo tempo entre emissor e receptor e suas coerências conversacionais. Portanto, não se pode separar os estudos da análise da conversação e a sociolinguística, justamente porque se trabalha a língua como objeto e suas diferentes variações lexicais, em diferentes contextos sociais e espaciais em que está inserida.

Para Calvet (2002, p. 89), as línguas mudam a cada dia que se passa, com possibilidade de evoluírem, apresentando aspecto diacrônico (que mudam conforme o tempo ou história) e, também, aspecto sincrônico (ao mesmo tempo). Um mesmo léxico pode ser pronunciado de várias maneiras em territórios diferentes, chamado de "variáveis geográficas" em que, como exemplo do Brasil, a palavra "osga" pode ser chamada no Norte de "briba", já no Nordeste a mesma palavra pode ser chamada de "víbora" e a mesma palavra em "lagartixa" no Centro-Sul. 
Calvet também menciona o que seriam "variáveis sociais", pela qual cada palavra pode representar uma hierarquia social em determinado país, e isso inclui a educação, profissão, grupos em que se convive e etc., podendo interferir e modelar a identidade pessoal de cada indivíduo de acordo com essas diferenças linguísticas.

Portanto, a variação linguística é representada pelas variações da língua que ocorrem através do espaço e tempo, pela qual a diversidade de uso da língua e seu uso é seu objeto de estudo, e isso pode ser influenciada a idade, sexo, escolaridade e localização geográfica de um indivíduo.

Para se entender melhor as variações linguísticas, primeiro deve-se entender o que seria língua (muitas vezes confundida com linguagem). Segundo Hora (2011), a definição de língua seria um conjunto de signos linguísticos usados por membros de uma mesma comunidade, apresentando sua linguagem própria, atrelando valores uns aos outros, um produto social com o objetivo de se comunicarem. Já linguagem é um processo de interlocução em que diferentes sociedades ou grupos realizam práticas sociais e são distintas conforme o tempo e espaço.

A língua representa formas variadas, com um conjunto de variedades próprias de uma determinada região ou grupo de falantes. A interação entre eles é sua realidade e isso implica, no caso da língua portuguesa, formas diferentes de se falar, sendo que não existem as formas corretas e as formas erradas, mas sim, são apenas diferentes e se fazem entender dessa diferença. Isso explica o fato dos jovens se comunicarem no meio virtual através de uma linguagem diferente, rápida, ágil e de urgência de informações, adaptando-se o falar para a escrita.

A conversa tem uma estreita relação com a escrita através da utilização da linguagem em meios virtuais, pois se usam estratégias conversacionais próprias e particulares e dependendo dos tipos de recursos e ferramentas que seus usuários possuem nesse ambiente, a interação pode acontecer de maneira diferente, com práticas e significados diferentes.

A exemplo do aplicativo WhatsApp, que é o objeto de estudo deste trabalho, nos direciona para um ambiente de mensagens instantâneas e conversação em tempo real, em que o usuário pode interagir com outros de maneira síncrona (semelhante a face-a-face) e assíncrona (podendo ocorrer em mais de um espaço temporal), com a possibilidade de um dos usuários estarem desconectados da Internet (AYRES, 2014).

Portanto, a variação linguística pode existir e se manifestar entre falantes de uma língua em determinado ambiente social, seja ele face-a-face ou virtual.

\section{Internetês}

O Internetês pode ser definido como uma adaptação linguística no contexto da comunicação ou diálogo virtual e tem por objetivo encurtar o tempo gasto em escrever certas 
palavras e sem perder o foco das informações que se passa no ambiente, sendo que este curto espaço de tempo requer também do usuário a apropriada abreviação gramatical na produção escrita, dispensando diretamente as formalidades (HORA, 2011).

Segundo Maciel (2008, p. 5), Internetês é um neologismo criado para definir a linguagem encontrada no meio virtual, pela qual existem vocabulários abreviados em uma, duas ou três letras, ignorando a norma gramatical de construção das palavras e dando a entender o significado desses vocabulários a partir dessas poucas letras. Isso se deu pelo fato da rápida comunicação e informação entre os jovens no âmbito das redes sociais, chats, blogs, vídeos etc., tornando-os mais interativos, mais dinâmicos, ágeis e facilitadores da escrita virtual, emprestando desta essa liberdade de expressão da fala por meio de textos escritos e construção de vocabulários e expressões próprias.

Segundo Reis (2013, p. 36), ela nos mostra alguns exemplos do Internetês e seu uso em conversas criadas no contexto do aplicativo WhatsApp, que podem ser iniciadas a partir de hábitos culturais, expressões que indicam risadas, gírias, palavrões, como mostram os exemplos a seguir:

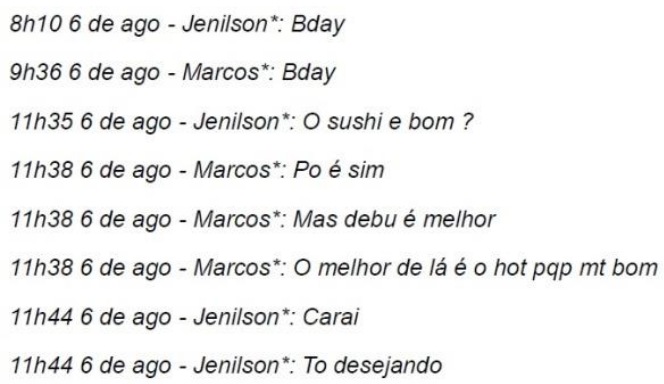

Figura 1: Diálogos do WhatsApp 1

Fonte: print screen em REIS, B. S. S. Brasília, 2013, p. 36.

Neste exemplo acima, se percebe o uso de algumas abreviações da língua portuguesa e podem ser identificadas como "Bday" (bom dia), "Po é" (pois é), pqp (puta que pariu), "mt" (muito), "Carai" (caralho).

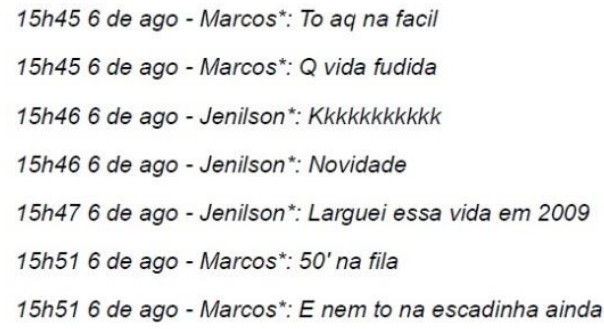

Figura 2: Diálogos do WhatsApp 2

Fonte: print screen em REIS, B. S. S. Brasília, 2013, p. 37.

Neste outro exemplo acima, podemos perceber mais alguns uso de abreviações de palavras do português, entre elas "To" (Estou), "aq" (aqui), "Q" (Que) e "kkkkkkkkkk" (expressão do sentimento de risada). 
Portanto, os dois exemplos dos diálogos no contexto do aplicativo WhatsApp acima nos revelam dados que podem ser analisados e discutidos para pesquisa sobre as variações da língua portuguesa. Além disso, nos mostra claramente que existem termos que podem ser abreviados e que podem ser usados no meio virtual nas interações com pessoas, pela qual a maioria dos participantes fazem uso delas e sabem o significado de cada uma delas.

Nesse sentido, o Internetês se mostra como um facilitador no uso dessa nova linguagem em meio ao avanço tecnológico e a rápida informação entre usuários, fazendo com que haja uma grande motivação, uma grande necessidade de se expressar e conversar de forma rápida e dinâmica, pois se precisa acompanhar a ideia de uma conversa virtual sem perder o foco. Mas para isso, é preciso certa habilidade de como trabalhar as palavras adequadamente e isso requer o conhecimento de uso de abreviações adequadas, do uso correto de certos vocabulários, o que muitos ainda não conhecem e ainda não sabem que estão utilizando.

\section{Metodologia}

Sendo uma proposta de pesquisa de campo, este trabalho teve o cunho qualitativo e quantitativo, com o objetivo de identificar quais eram as variações linguísticas encontradas no âmbito virtual e nas suas interações de comunicação, especificamente mediante a utilização do aplicativo WhatsApp e usuários desta plataforma.

Os participantes desta pesquisa foram seis jovens e cinco adultos, escolhidos aleatoriamente e que usavam ativamente o aplicativo em seus celulares ou smartphones, fazendo parte de um contexto virtual de interação e conversas online, além de fazerem parte de grupos de conversas particulares ou restritos como de amigos, da família, da faculdade etc.

Os procedimentos de coleta de dados se deu em três fases: a primeira fase da pesquisa se deu com a escolha aleatórias dos participantes desta plataforma, na qual foram explicados todas as informações sobre a pesquisa em geral, assim como o propósito da mesma e dados relevantes. A segunda fase da pesquisa se deu através de entrevistas com conversas particulares dentro do aplicativo, pela qual eu participei como entrevistador juntamente com usuários do aplicativo WhatsApp e submeti um questionário contendo seis perguntas semiestruturadas relativas ao objetivo desta pesquisa. A terceira fase da pesquisa se deu através da coleta de dados e análise dos dados juntamente a triangulação com os referenciais teóricos.

Os instrumentos de pesquisa utilizados foram a aplicação de questionário e entrevista e virtual, além da utilização de papel A4, caneta, lápis, borracha, caderno, computador, Internet e impressora, conforme a necessidade que a pesquisa demandou durante seu processo de elaboração e execução. O custeio dos materiais necessários para esta pesquisa se deu pelo próprio pesquisador. 


\section{Análise e discussão dos dados} WhatsApp.

Nesta sessão, mostram-se os resultados das entrevistas feitas no contexto do aplicativo

A primeira pergunta da entrevista foi "A conversa ou comunicação entre as pessoas acontece tanto no modo face-a-face quanto no modo virtual. Na sua opinião, quais dos dois modos você prefere ou mais utiliza para uma conversa ou comunicação com outras pessoas?". As respostas poderiam ser escolhidas com mais de uma alternativa, como são apresentadas na tabela a seguir:

\begin{tabular}{cc}
\hline Resposta & Quantidade \\
\hline face-a-face & 1 \\
virtual & 2 \\
ambas & 9 \\
\hline
\end{tabular}

TABELA 1: Respostas da pergunta $n^{\circ} 1$

De acordo com a tabela um, um participante respondeu que prefere a conversa face-aface, dois participantes responderam que preferem a conversa virtual e nove participantes responderam que preferem ambas para uma conversa com as pessoas.

Desta forma, percebemos que a conversação se faz presente de um modo recíproco e inevitável para as pessoas, pois como Hilgert (apud MODESTO, 2011, p. 20) menciona, a conversação se baseia na comunicação prática e cotidiana, sendo que os interlocutores desenvolvem um processo de vai e vem de mensagens e sempre há uma regra de comportamentos entre os participantes da conversa.

A segunda pergunta da entrevista foi "Dentre a(s) sua(s) resposta(s) da questão anterior, quais fatores estão inseridos na sua opinião?". As respostas poderiam ser escolhidas com mais de uma alternativa, como são apresentadas na tabela a seguir:

\begin{tabular}{cc}
\hline Resposta & Quantidade \\
\hline importância da conversa & 7 \\
liberdade de expressão & 3 \\
facilidade de uso da língua & 2 \\
divertimento da conversa & 3 \\
outros & 2 \\
\hline
\end{tabular}

TABELA 2: Respostas da pergunta $\mathrm{n}^{\mathrm{o}} 2$

De acordo com a tabela dois, sete participantes responderam que a importância da conversa é um fator para a interação face-a-face e virtual, três responderam que o fator é a liberdade de expressão, dois responderam que a facilidade de uso da língua é o fator para a 
interação, três responderam que o divertimento da conversa é o fator para a interação acontecer e dois responderam outros.

Sendo assim, o maior fator para a utilização da conversa ou comunicação com outras pessoas, tanto face-a-face quanto virtual, é o grau de importância da conversa, sendo que a liberdade de expressão e o divertimento da conversa vêm acompanhados como fatores que também fazem parte de suas escolhas. Nesse sentido, busca-se o que Marcuschi (2001, p. 15) menciona sobre isso, que os participantes da conversa levam em conta fatores inerentes a eles como a cognição, o grau de importância da conversa, o valor visual e os tipos de tarefas comuns que ambos procuram desenvolver e solucionar e talvez por isso que a importância da conversa seja um dos maiores fatores para ocorrer a comunicação face-a-face e a comunicação virtual.

A terceira pergunta da entrevista foi "Na sua opinião, você sabe o que é Internetês?". As respostas são apresentadas na tabela a seguir:

\begin{tabular}{cc}
\hline Resposta & Quantidade \\
\hline Sim & 7 \\
Não & 4 \\
\hline
\end{tabular}

TABELA 3: Respostas da pergunta $\mathrm{n}^{\circ} 3$

De acordo com a tabela três, sete participantes responderam que "sim", conhecem o termo Internetês e quatro participantes responderam "não".

Portanto, a maioria dos participantes sabe do que se trata este termo no contexto virtual e fazem uso dela dentro das conversas mediadas pelo aplicativo WhatsApp. Porém, não se soube realmente se eles sabiam a sua definição ou se disseram "sim" pela semelhança da palavra Internet, relacionando com algo pertencente à ela. Por outro lado, os outros participantes desconheciam o termo, mesmo que, talvez, estivessem utilizando-a de forma inconsciente no contexto do aplicativo.

A quarta pergunta da entrevista foi "O Internetês é uma adaptação da língua encontrada no meio virtual para vocabulários abreviados em uma, duas ou três letras, dando a entender o significado desses vocabulários a partir dessas poucas letras. Na sua opinião, a utilização dessas palavras abreviadas (como pq, vc, tb, etc.) é importante para suas conversas via o aplicativo WhasApp? Por que?". As respostas são apresentadas na tabela a seguir:

\begin{tabular}{cc}
\hline Resposta & Quantidade \\
\hline Sim & 9 \\
Não & 2 \\
\hline
\end{tabular}

TABELA 4: Respostas da pergunta ${ }^{\circ} 4$

De acordo com a tabela quatro, nove participantes responderam que "sim" e dois responderam que "não". Dentre os nove participantes que responderam "sim", a maioria 
mencionou que é importante o uso de abreviações de palavras do português nesse contexto por ser mais rápido e por tomar menos tempo de quem está conversando, além de apresentar uma forma dinâmica e a necessidade da praticidade do uso da língua.

Isso confirma o que Maciel (2008, p. 5) diz a respeito de Internetês, que se desenvolve pela necessidade da rápida comunicação e informação entre os jovens nos dias atuais diante dos computadores com conexão da Internet, tornando-os mais interativos e fazendo-os mais dinâmicos, ágeis e facilitadores da escrita virtual, emprestando desta essa liberdade de expressão da fala por meio de textos escritos e construção de vocabulários e expressões próprios.

Já dentre os dois participantes que responderam "não", eles argumentaram que não acham viável utilizar abreviações da língua portuguesa, mesmo sendo no contexto do aplicativo WhatsApp, pois alegaram que valorizam a escrita e que esse costume acaba fazendo com que a maioria das pessoas esqueça como se escreve realmente a língua portuguesa e a pessoa consegue atrair um costume ruim por esta causa.

A quinta pergunta da entrevista foi "Dentre as palavras do português abreviadas utilizadas no aplicativo WhatsApp e na sua opinião, quais são as que você mais utiliza?”, na qual foi uma pergunta aberta e os participantes puderam opinar a respeito das abreviações de palavras do português. O resultado desta pergunta pode ser visto no gráfico abaixo:

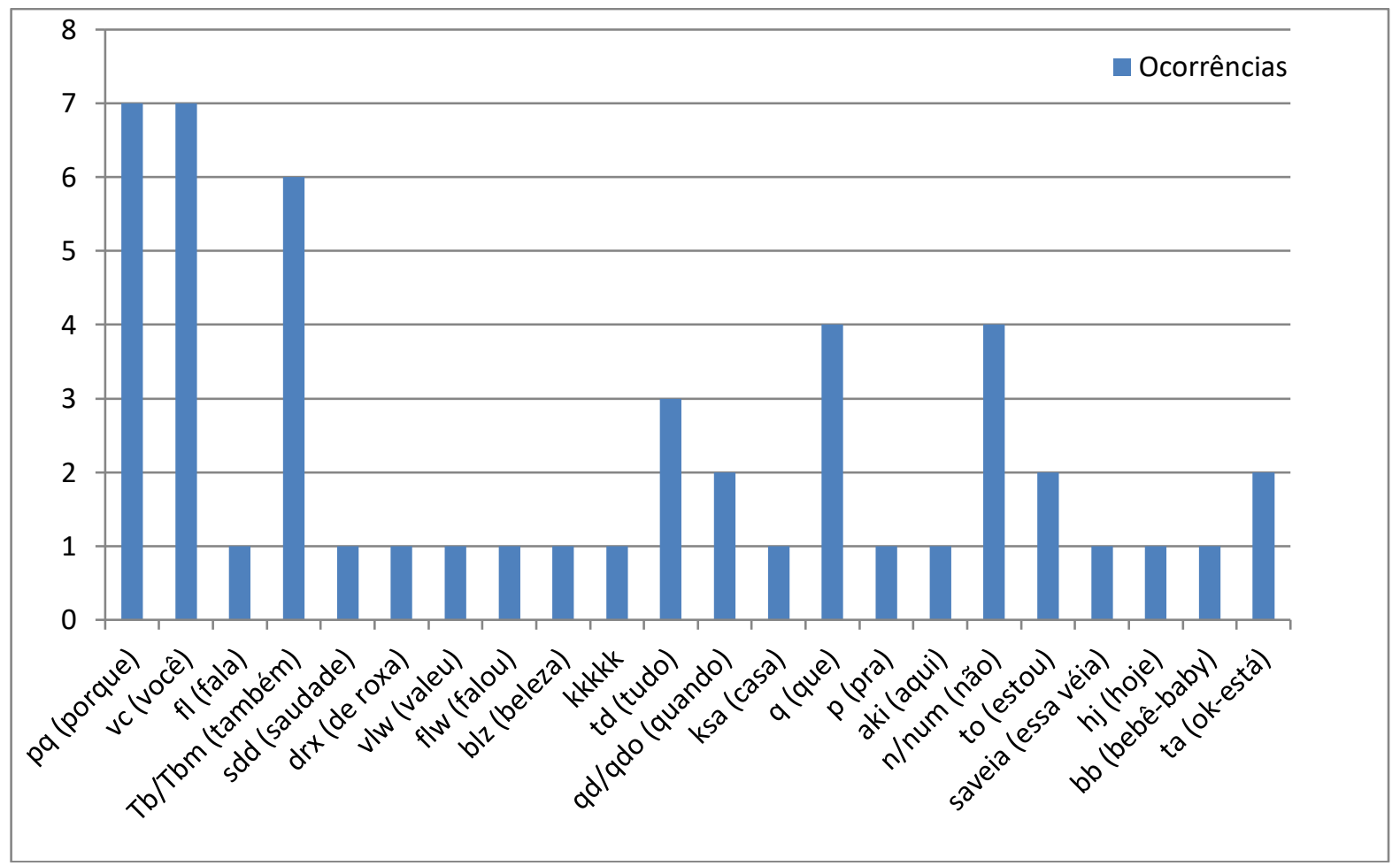

Gráfico 1: Ocorrências de palavras abreviadas mais utilizadas no aplicativo WhatsApp.

O gráfico um representa todas as palavras abreviadas que os participantes da entrevista mais utilizavam nas conversas do aplicativo WhatsApp, separados e postos por graus de ocorrências em que cada um é mencionado. Nele, se percebe que as ocorrências maiores são 
do "pq" e do "vc" (sete ocorrências), enquanto que "tb/tbm" com menos ocorrências (seis ocorrências). Os termos "q" e "n/num" ficaram com quatro ocorrências, enquanto que os outros termos são utilizados poucas vezes.

Nesse contexto, reafirmamos o que Reis (2013, p. 36) diz sobre as interações e o uso de abreviações em certas conversas via WhatsApp, mostrando uma necessidade de ganhar tempo e escrever da forma mais rápida possível, justamente para acompanhar o ritmo do assunto dentro dessas conversas, especialmente se a participação estiver ocorrendo através de um determinado assunto em um grupo do aplicativo, levando em conta os fatores culturais, gírias, palavrões etc.

A sexta pergunta da entrevista foi "Com relação a essas palavras abreviadas, com quem e em que contextos você mais as utiliza no aplicativo WhatsApp? Por que?". As respostas poderiam ser escolhidas com mais de uma alternativa, como são apresentadas na tabela a seguir:

\begin{tabular}{cc}
\hline Resposta & Quantidade \\
\hline amigos & 10 \\
conhecidos & 4 \\
família & 7 \\
grupos & 6 \\
outros & 0 \\
\hline
\end{tabular}

TABELA 5: Respostas da pergunta $\mathrm{n}^{\circ} 6$

De acordo com a tabela cinco, dez dos participantes escolheram a opção "amigos"; quatro escolheram a opção "conhecidos", sete escolherem a opção "família" e seis escolheram a opção "grupos". A opção "outros" não foi selecionada.

Nesta mesma pergunta se quis saber o porquê dos participantes usarem as palavras abreviadas da língua portuguesa nesses contextos e comentaram que eles se sentem com mais liberdade durante as conversas, de se expressarem melhor, pela rapidez que podem conversar, pela facilidade da comunicação à distância com um conhecido, pelo dinamismo que grupos podem apresentar e pela redução de tempo gasto em escrever certas palavras.

\section{Conclusão}

Nesta presente pesquisa, se identificou as variações da língua portuguesa mais comuns no contexto de conversas do aplicativo WhatsApp e notou-se que existem diversas formas e termos de expressão para a língua portuguesa, que pode facilitar a interação da comunicação, seja ela pelos fatores de rapidez, de facilidade, de preferências, seja ela pela comodidade, pelo dinamismo e pela praticidade do uso da língua. O ser humano se relaciona com seus semelhantes através da comunicação, da interação entre pessoas, sempre com propósitos e objetivos, seja ele no contexto real ou no contexto virtual da Internet. 
Entre os dados mencionados, se nota que há, além da variação da língua, variedades de vocabulários no contexto virtual, como as palavras "n" e "num", que ambas significam "não", e também entre as palavras "tb" e "tbm", ambas significando "também". Nesse sentido, concorda-se com Calvet (2002) que diz que as línguas mudam a cada dia que se passa, com possibilidade de evoluírem e que um mesmo léxico pode ser pronunciado de várias maneiras em territórios diferentes.

Concorda-se com o que os autores Scaramal e Kraemer (2011, p. 2) mencionam sobre a interação no meio virtual, pois as universidades, como espaço de conhecimento, construção e contextualização da realidade social, não podem deixar de lado a questão da influência em que as comunicações e informações, presentes no meio virtual, são recorrentes e fazem parte dessa realidade social, pois esta tendência é importante para os estudos da linguagem e podem ser consideradas importantes para pesquisas nessas instituições, podendo conscientizar seus alunos para o seu uso adequado na interação real e na interação virtual.

Assim, a linguagem utilizada no meio virtual está diretamente atrelada ao tempo e espaço da interação existente, sendo necessária a abreviação de palavras para uma interação virtual síncrona em que requer agilidade e rapidez do usuário. Neste meio, esquecem-se as regras gramaticais e normas imposta pela sociedade e valendo-se da informalidade, em que, para muitos, é a forma simples de expressar seus sentimentos diversos.

A variação linguística deve ser enxergada de um modo respeitado pela sociedade, não importando se for dentro ou fora da sala de aula, de casa, de estado, de país, pois se acredita que é impossível a manutenção de um paradigma da língua falada em se tratando das diversas regiões do nosso país. Para tanto, a variação é importante entre a população e não menospreza e nem tão pouco engrandece uma determinada língua, ela dá a oportunidade de compreensão de mundo, sua relação e característica na sociedade com seu grau de conhecimento.

\section{Referências}

AYRES, M. A conversação em tempos de WhatsApp. Grupo de pesquisa em interação, tecnologias digitais e sociedade. Set. 2014. Disponível em: <http://gitsufba.net/a-conversacaoem-tempos-de-whatsapp/>. Acesso em: 15 set. 2015.

CALVET, L. Sociolinguística: uma introdução crítica. Parábola. São Paulo: Parábola Editorial, 2002.

FERREIRA, L. C. R. Whatsapp Messenger: a tool to motivate students in English language writing. 2013. 36 f. Trabalho de Conclusão de Curso (Licenciatura em Línguas Inglesa) - Instituto de Letras e Comunicação, Universidade Federal do Pará, Belém.

HORA, M. S. A variação linguística na internet: as aventuras e desventuras da linguagem virtual no cotidiano escolar. Artigonal, 2011. Disponível em: <http://www.artigonal.com/ensino-superior-artigos/a-variacao-linguistica-na-internet-asaventuras-e-desventuras-da-linguagem-virtual-no-cotidiano-escolar-5363461.html>. Acesso em: 17 ago. 2015. 
KRAEMER, A.; SCARAMAL, J. A influência da internet nas variações linguísticas. Encontro Nacional de Informática e Educação, 2011. Disponível em:

<http://www.inf.unioeste.br/enined/anais/artigos_enined/A42.pdf>. Acesso em: 16 set. 2015.

LAHM, R.; PINHO, D.; RIBAS, Â.; RIBAS, E. A influência da linguagem virtual na linguagem formal de adolescentes. Revista Renote: novas tecnologias na educação. Rio Grande do Sul, v. 5, n. 1, jul. 2007. Disponível em:

<http://www.cinted.ufrgs.br/ciclo9/artigos/8dElisangela.pdf>. Acesso em: 16 ago. 2015.

MACIEL, J. W. G. Internetês: variação linguística ou modismo computacional? Grupo de estudo sobre hipertexto, arquivos eletrônicos e tecnologia educacional, Ago. 2008. Disponível em: 〈http://gehaete.uepb.edu.br/trabalhos/2008/ago/1.pdf>. Acesso em: 14 set. 2015.

MARCUSCHI, L. A. Análise da Conversação. 5. ed. São Paulo: Ática, 2001.

MODESTO, A. T. T. Processos interacionais na Internet: análise da conversação digital. 2011. p. 191. Tese do Programa de Pós-Graduação em Filologia e Língua Portuguesa Departamento de Letras Clássicas e Vernáculas, Universidade de São Paulo. São Paulo.

OLIVEIRA, C. M. Caracterização do gênero chat através do aplicativo WhatsApp. In: $5^{\circ}$ Simpósio Hipertexto e Tecnologias na Educação. 2013. Universidade Federal de Pernambuco. Disponível em: <http://www.nehte.com.br/simposio/anais/Anais-Hipertexto2013/CARACTERIZA\%C3\%87\%C3\%830\%20DO\%20G\%C3\%8ANERO\%20CHAT\%20A TRAV\%C3\%89S\%20DO\%20APLICATIVO\%20WHATSAPP.pdf>. Acesso em: 19 set. 2015.

POLLARD, A. Increasing awareness and talk time through free messaging apps. English Teaching Forum. United States, v. 53, n. 1, p. 25-32. 2015.

REIS, B. S. S. "Você tem WhatsApp?" Um estudo sobre a apropriação do aplicativo de celular por jovens universitários de Brasília. 2013. 79 f. Monografia (Comunicação social) - Faculdade de Comunicação da universidade de Brasília. Brasília. 
